\title{
The COVID-19 lockdown does not necessarily worsen diabetes control, in spite of lower physical activity a systematic review
}

\author{
Abdulrhman Aldukhayel ${ }^{\circledR}$ \\ Department of Family and Community Medicine, College of Medicine, Qassim University, Buraydah, Saudi Arabia
}

\begin{abstract}
Introduction: This review aimed to synthesize evidence on the impact of the COVID-19 lockdown on the glycaemic control, physical activity, and diet of diabetic patients.

Material and methods: Two electronic databases (PubMed and Scopus) were searched from January 2020 to February 2021. A total of 161 unique records were retrieved. Out of these, 25 articles met the eligibility criteria and were included in the final review. The quality of the studies was assessed by using the modified Newcastle-Ottawa Quality Assessment Scale for observational studies.

Results: Out of the 25 studies included in the review, $18(72 \%)$ were cross sectional, $5(20 \%)$ were retrospective analyses, and $2(8 \%)$ were cohort studies. Thirteen studies included type I diabetics, 8 studies included type II diabetics, and 4 studies included both. In the quality assessment, $17(68 \%)$ of the studies met the criteria of satisfactory quality. Overall glycaemic parameters were improved during the lockdown. Dietary patterns were affected during the lockdown, but the direction of change - either negative or positive — could not be inferred. However, physical activity patterns were found to be deteriorated during the lockdown.

Conclusion: The review found that lockdowns for curbing COVID-19 had no negative impact on glucose control, while there was a decline in the physical activity among diabetics. Furthermore, available studies are subject to various biases, which calls for robust studies in future with representative samples. There is also a need to promote physical activity and a healthy diet among diabetic patients, with follow-up through telemedicine during such confinement periods. (Endokrynol Pol 2022; 73 (1): 131-148)
\end{abstract}

Key words: COVID-19; diabetes; physical activity; diet; glycaemia; control

\section{Introduction}

The Corona virus disease 2019 (COVID-19) has affected all aspects of life directly and indirectly. Since its beginning, it has affected more than one billion people and caused nearly 3 million deaths globally [1]. In order to curb the rapid spread of disease, many measures were taken, which ranged from personal protection through masks to restriction of activities and complete lockdowns at national and sub-national levels [2]. These measures were aimed at reducing the transmission, but also resulted in economic hardship, especially for low income people, and difficult access to health care $[3,4]$.

The health care delivery system was also affected in more than one way, e.g. diversion of resources for acute care of COVID-19 cases, mobility of health care personnel, risk of infection at health care facilities, and the shutdown of normal care provision specially in outpatient clinics and non-acute care settings [5, 6].

Chronic diseases require long-term and continuous treatment in order to control the disease and prevent complications. The COVID-19 pandemic, however, dis- rupted this care, and patients with chronic diseases faced difficulties in obtaining medicine, follow-up, and monitoring of diseases status. Diabetes is a common chronic disease globally, with about 463 million people affected [7]. These diabetics need continuous care and must maintain a healthy lifestyle, such as diet and physical activity, in order to keep glucose levels within normal ranges. Failure to do so may result in another pandemic of complications, mortality, and increased burden on health systems [8].

Service delivery and access to care have been affected by COVID-19. Furthermore, lockdowns and movement restrictions might also have affected people's lifestyles. These factors may affect the glycaemic control among diabetic patients. However, studies from different parts of the world have shown varying results. Some have shown improvement in glucose levels, while others have reported deterioration amid COVID-19 lockdowns. It is therefore necessary to synthesize the evidence and see how lockdowns have affected the diabetics. This systematic review therefore aimed to assess the impact of COVID-19 lockdown on the glycaemic control, physical activity, and diet of diabetic patients. 


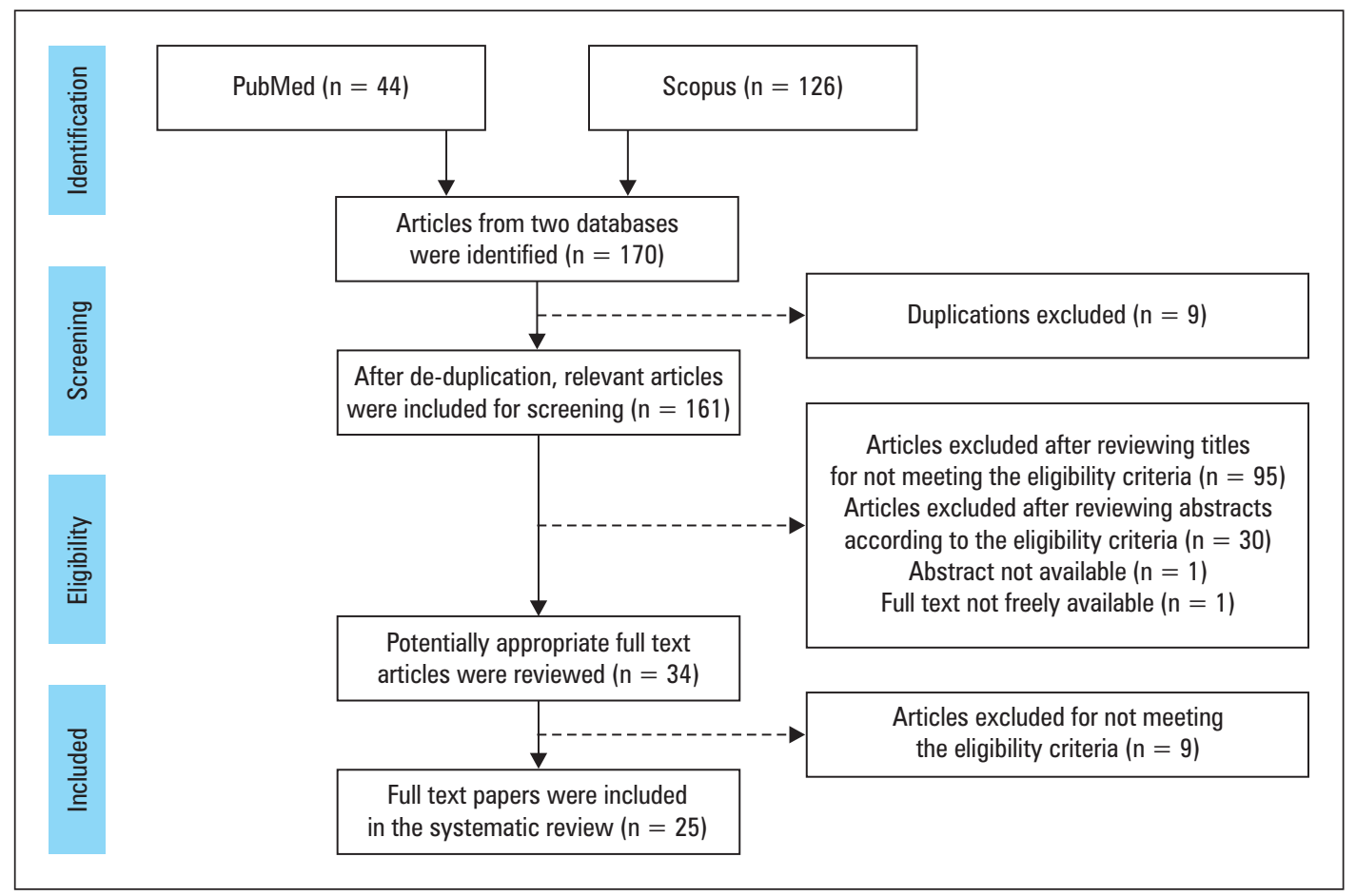

Figure 1. Flow diagram showing identification and selection of studies in the review

\section{Literature search}

An electronic literature search was carried out systematically for the impact of COVID-19 lockdown on the glycaemic control, dietary habits, and physical activity of diabetic patients during the COVID-19 pandemic.

\section{Eligibility criteria}

We included studies involving target groups of diabetic patients, both type I and II, under treatment during the pandemic, with the outcomes demonstrating in at least one of them in study outcomes: change in glycaemic control, physical activity, and dietary pattern. The studies comprised comparative cross sectional, case-control, cohort studies, quasi-experimental and before and after (pre-post), and randomized controlled trials. All published literature across all countries in the English language was included, and the duration of the review was from January 2020 to February 2021.

Studies were excluded if they targeted adolescents, diabetes during pregnancy, studies in other languages, without an abstract, no full texts available, not free of cost, and those that did not mention the COVID-19 lockdown duration. Case studies, symposium proceedings, editorials, commentaries, and opinions were also excluded.

\section{Information sources and search strategy}

A systematic search was conducted from two international electronic databases, i.e. PubMed and Scopus, using a detailed search strategy. Medical subject heading $(\mathrm{MeSH})$ terms were used where applicable for uniformity in search terms. The Boolean operators "AND" and "OR" were used. The search terms categorized under four categories and search strategy applied for this review are illustrated in Supplement 1.

\section{Study selection}

Full records were retrieved from the selected databases. After removing duplicates, unique records were available for screening. During screening, entries were removed based on title, and records were removed after screening the abstract. Further records were removed after a review of the full text or if the full text was not available. Final studies were included in the review. The procedure of study screening and selection are illustrated in Figure 1.

\section{Data collection process}

The reviewer screened the titles, abstracts, and full text of the selected studies according to the inclusion and exclusion criteria using an adapted and modified data-extraction form. The data-extraction form was developed on MS Excel using existing literature. The information extracted included the author, year of publication, study title, purpose of study, study setting, study design, study population, sampling technique, sample size, key outcome measures - change in glycaemic control and/or physical activity and/ or dietary pattern, key study findings, study limitations, key study conclusion and recommendations, reviewers' comments, and quality appraisal of included studies. (Suppl. 2)

\section{Quality assessment of included studies}

All the relevant full texts of the included studies were examined for quality using the 'Newcastle-Ottawa-Quality Assessment Scale' adapted for cross-sectional and cohort studies. [9] This scale was used to assess the quality by examining potential sources of bias in the selection, comparability of participants, and the assessment of outcomes, awarding scores out of ten possible points. The higher score indicating the higher quality; scores (9-10) "very good", (78) "good", (5-6) "satisfactory", and (0-4) "unsatisfactory" quality.

\section{Results}

\section{Study selection}

A total of 170 records were retrieved from selected databases. After removing 9 duplicates, 161 unique records were available for screening. During screening, 95 entries were removed based on title and 31 records 
were removed after screening the abstract. A further nine records were removed after a review of the full text, while for one study the full text was not available. Finally, 25 studies were included in the review. The results of study screening and selection are illustrated in Figure 1.

\section{Characteristics of included studies}

Out of 25 study included in the review 18 (72\%) were cross sectional, five $(20 \%)$ studies were retrospective analysis [10-14] and two (8\%) studies were cohort [15, 16] Only two studies $[17,18]$ employed simple random sampling while remaining used convenience sampling. In 13 studies the population was type I diabetics, 8 studies included type II diabetics, while 4 studies included type I and II diabetics. Sample sizes in the included studies ranged from 30 to 2510 participants, and 9 studies had sample sizes of less than 100 participants. Three studies recruited participants online, while the rest of the studies recruited participants or their data from health care facilities. The highest number of studies were from India $(n=8)$, followed by Italy $(n=7)$, and Spain $(\mathrm{n}=4)$. Other countries included Saudi Arabia (n = 2), the Netherlands (1), Scotland (1), Turkey (1), and Brazil (1) (Tab. 1).

\section{Quality of included studies}

In the quality assessment, 8 studies (32\%) were found to be unsatisfactory [16, 19-25] and $17(68 \%)$ studies met the criteria of satisfactory quality using NOS quality assessment criteria. The major sources of bias were representativeness $(n=24)$, control of potential confounders ( $\mathrm{n}=24)$, and unpowered sample size ( $\mathrm{n}=21)$. (Supplement: Quality assessment). Ten (40\%) of the studies did not objectively measure the outcomes.

\section{Findings of included studies (Tab. 2, 3) Glycaemic control}

The findings and conclusions of individual studies are presented in Table 2. Mean glucose was reported in 14 studies, out of which, 5 reported an increase [18, 26-29], 7 reported a decrease [10,12, 14, 30-33], and 3 studies reported no change $[20,21,30]$ in mean blood glucose level during lockdown compared to pre-lockdown. The coefficient of variation (CV), which indicated glucose variability, was reported in eight studies, of which two reported a decrease $[14,20]$ while six reported no change [12, 21, 30-33]. Fasting blood sugar (FBS) levels were reported to increase in three studies [13, 15, 24], decrease in one study [17], while one study showed no change [23]. Post-prandial blood sugar (PPBS) was found to increase in three studies $[13,23,24]$ and decrease in two studies $[15,17]$. Glycosylated haemo- globin $\left(\mathrm{HbA}_{1 \mathrm{c}}\right)$ was reported in 12 studies, out of which 3 reported significant increase [13, 24, 27], 6 reported a decline [14-17, 32, 33], while 3 studies reported no change in the $\mathrm{HbA}_{1 \mathrm{c}}$ levels $[20,21,34]$. The Glucose Management Indicator (GMI) was reported in 5 studies. Out of these studies, one reported no significant change in GMI [11] while four reported a decrease in GMI $[10,12,14,31]$. Glucose levels time in range (TIR) $\%$ was reported by 12 studies. The majority (9) of studies showed an increase in TIR [10, 12, 14, 16, 20, 30-33]. Only one reported a decrease [27] and two reported no significant change in TIR\% [21, 30]. Overall glycaemic parameters were improved during the lockdown, as seen by larger number of studies showing a decline in mean glucose levels and $\mathrm{HbA}_{1 \mathrm{c}}$ levels. On the other hand, TIR\% also increased in most of the studies, with corresponding changes in TAR and TBR percentages.

Out of 17 studies that met the criteria of satisfactory quality, 7 studies reported $\mathrm{HbA}_{1 \mathrm{c}}$ while 10 studies reported other indicators of glycaemia such as blood glucose, mean glucose, and glucose monitoring indicator. Five studies reported a decline in $\mathrm{HbA}_{1 \mathrm{c}}$ levels [14, $15,17,32,33]$ while two studies reported no significant change in the $\mathrm{HbA}_{1 \mathrm{c}}$ levels $[13,34]$. Among the studies reporting other measures of glycaemia, five studies reported a decline [10-12, 30,31] and five reported an increase in glucose levels during lockdown [18, 26-29]. This indicates an overall improvement in the glycaemic control.

\section{Changes in dietary pattern}

Out of 25 included studies, 10 reported changes in the dietary patterns. Four studies reported a negative impact on diet $[19,24,25,29]$ during lockdown, while one study reported no change in the dietary patterns [10]. Five studies, however, just reported the change without indicating the direction of change $[18,20,22$, $23,34]$. Dietary patterns were affected by the COVID-19 lockdown. However, it is difficult to infer from available literature whether it was negatively affected or not.

\section{Changes in physical activity pattern}

Physical activity (PA) as an outcome was reported in 13 studies. One study [15] reported an increase in the PA levels while most $(n=11)$ studies reported decline in the PA levels during lockdown compared to pre-lockdown. [16, 17, 19, 20, 22, 24-29] One study only reported the change without indicating the direction of change [23]. Overall, PA patterns deteriorated during lockdown.

Among the 17 studies that were of satisfactory quality, 6 reported physical activity. Out of these, only one 


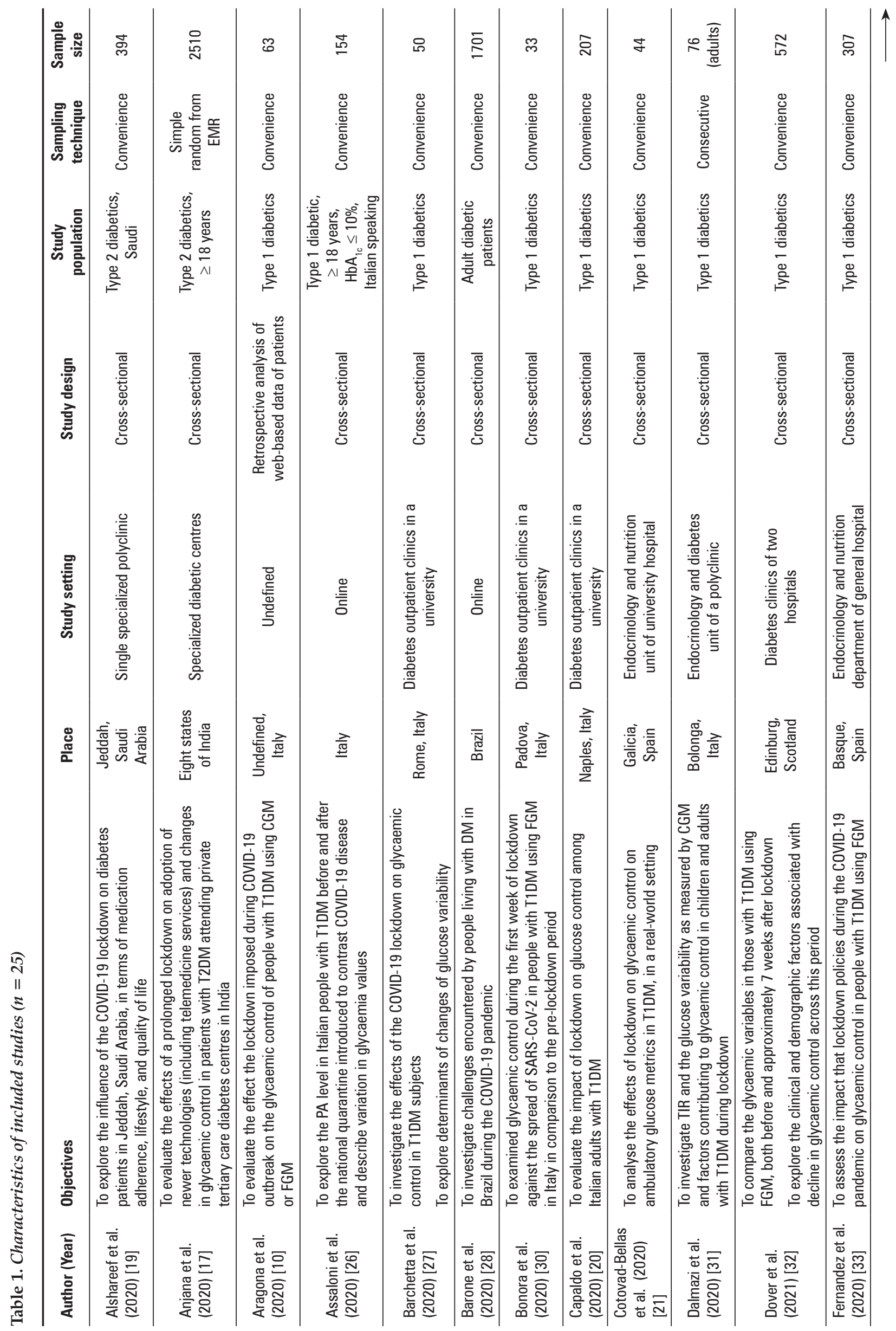




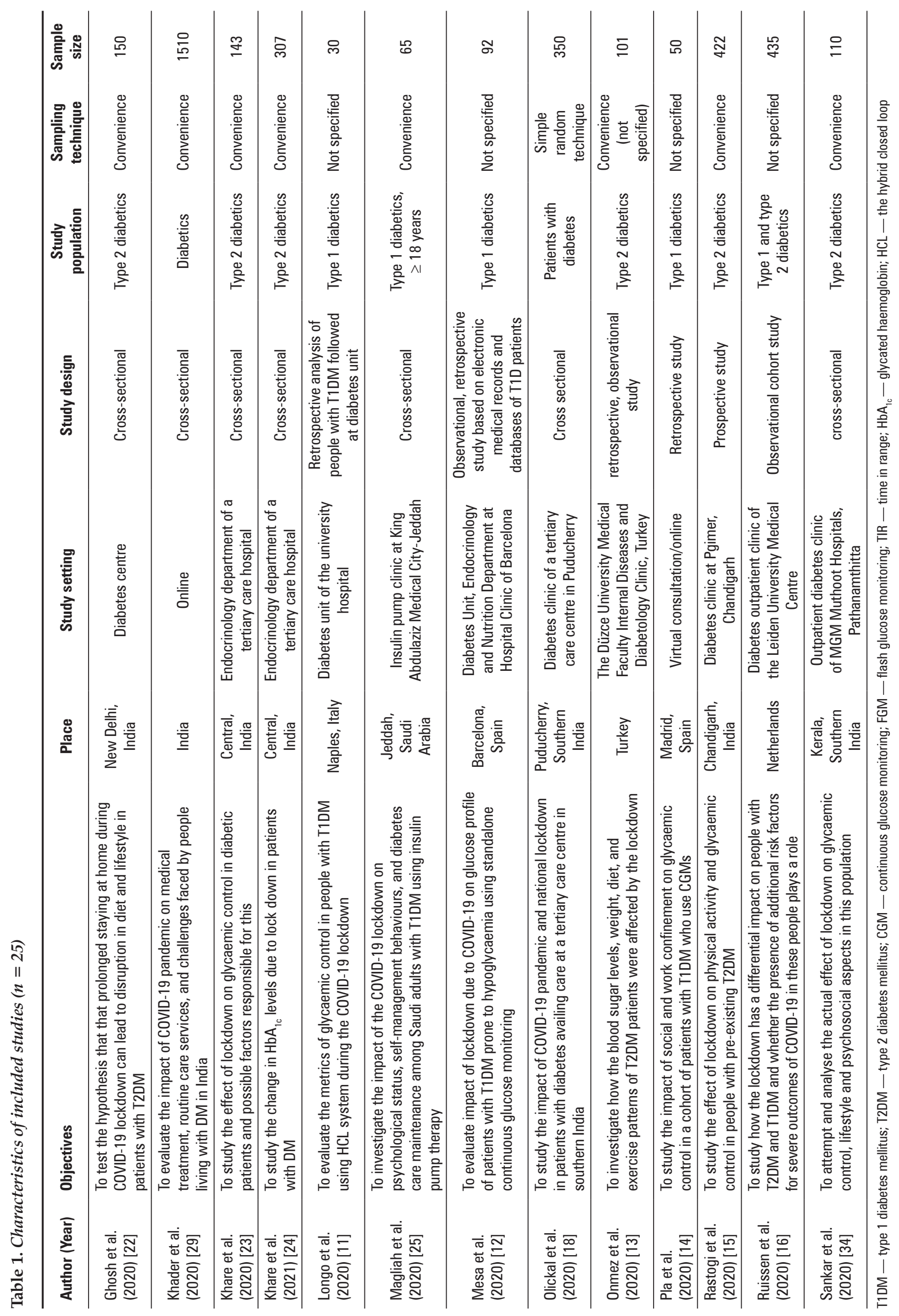




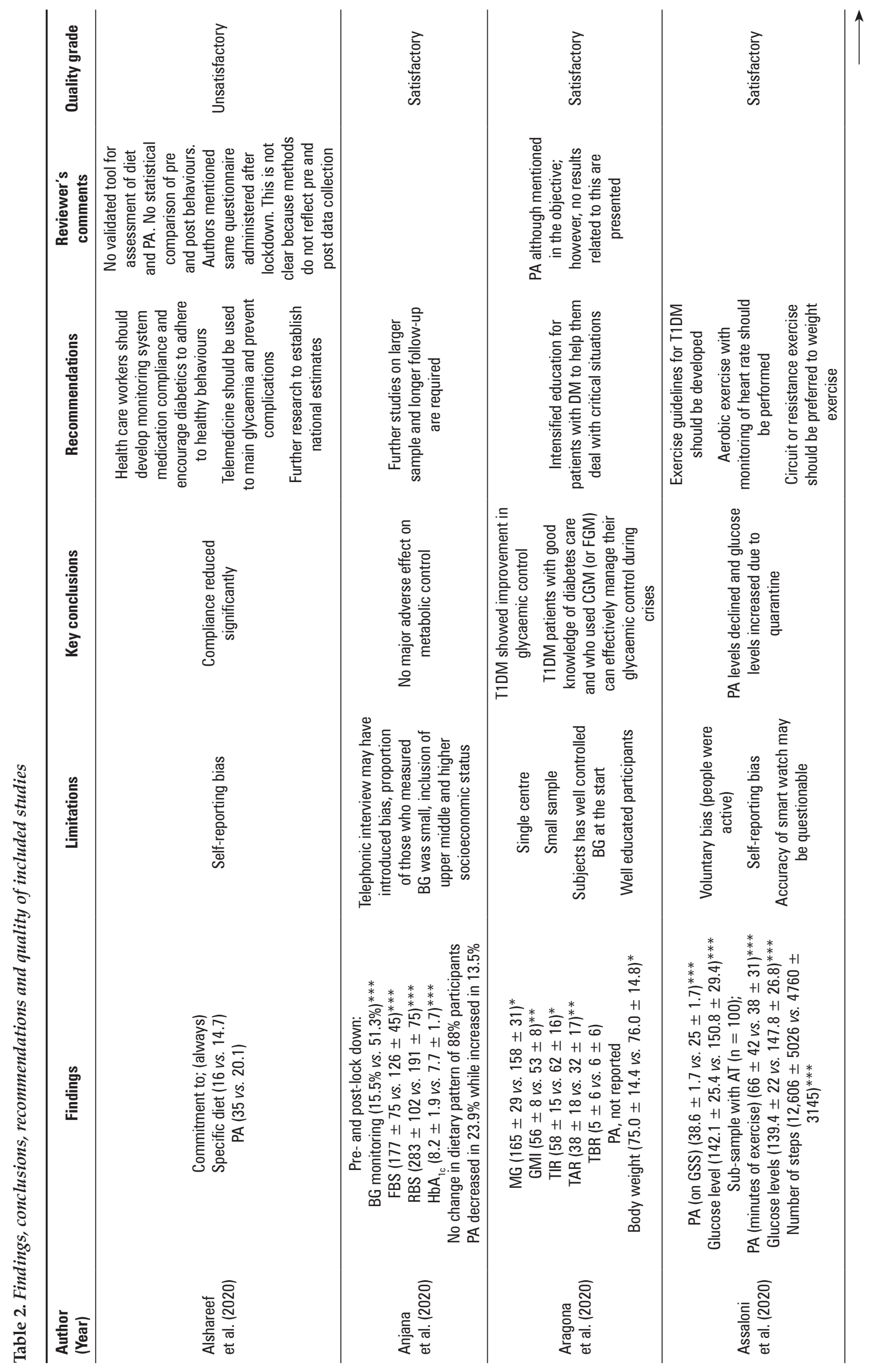




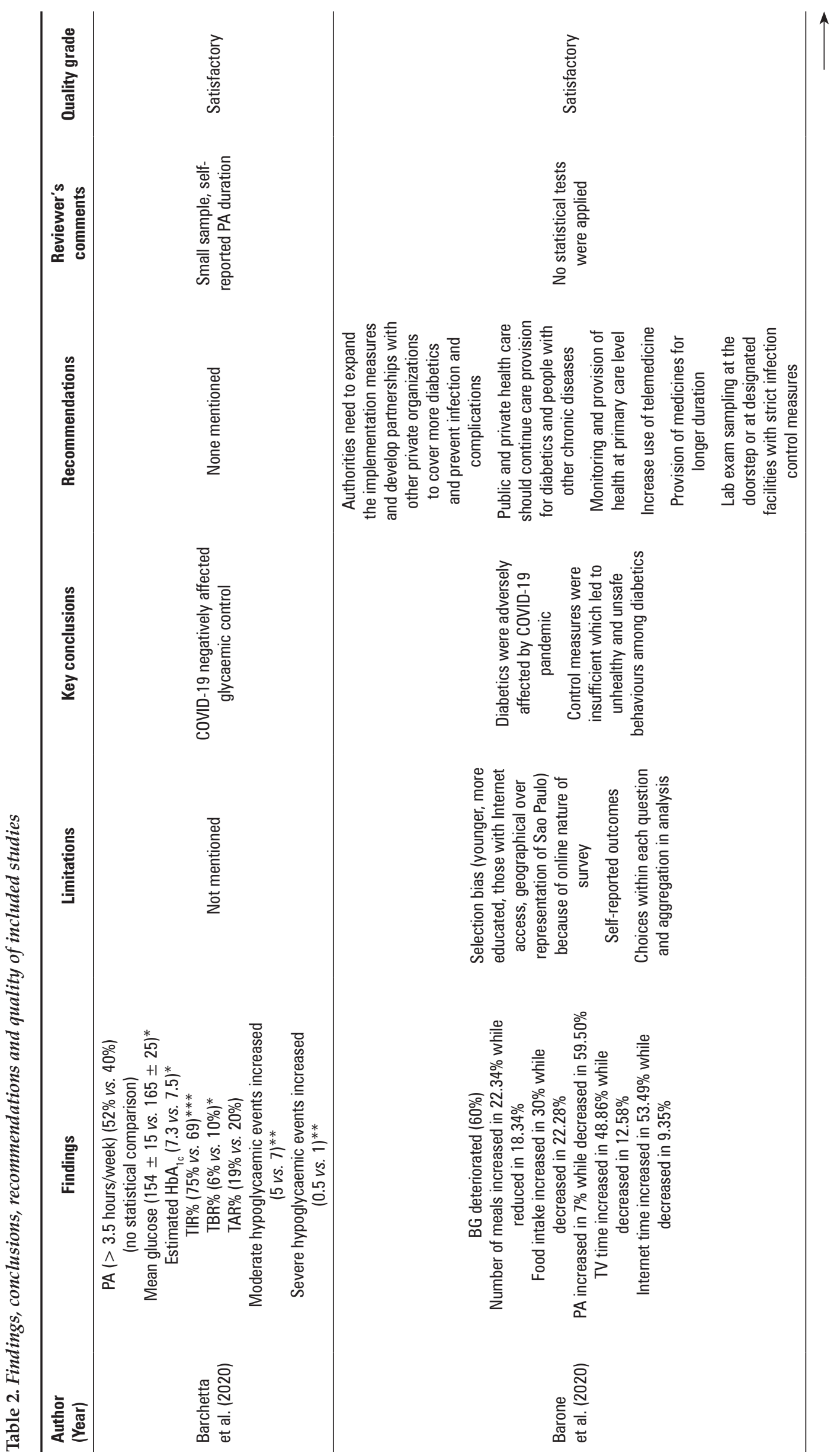




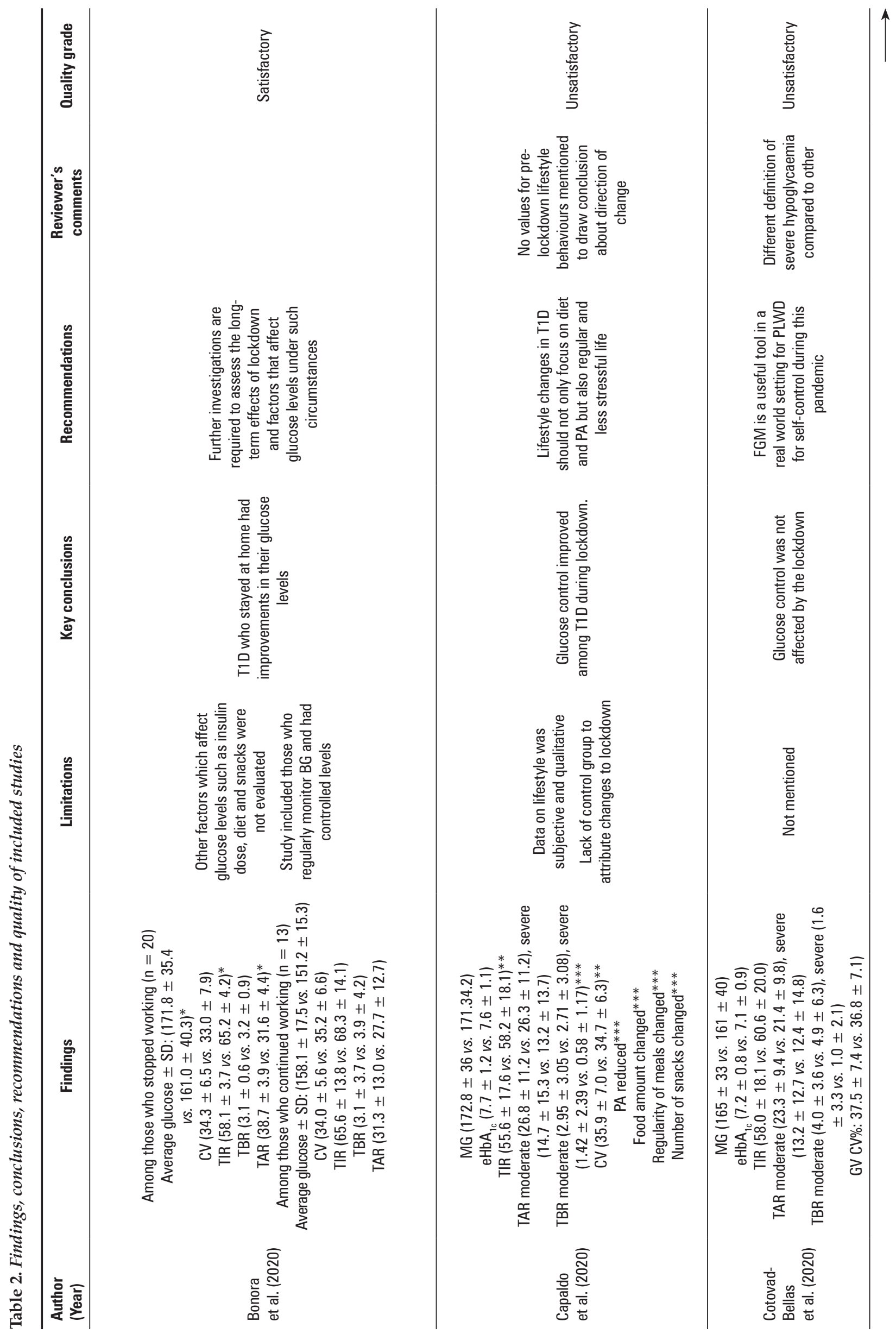




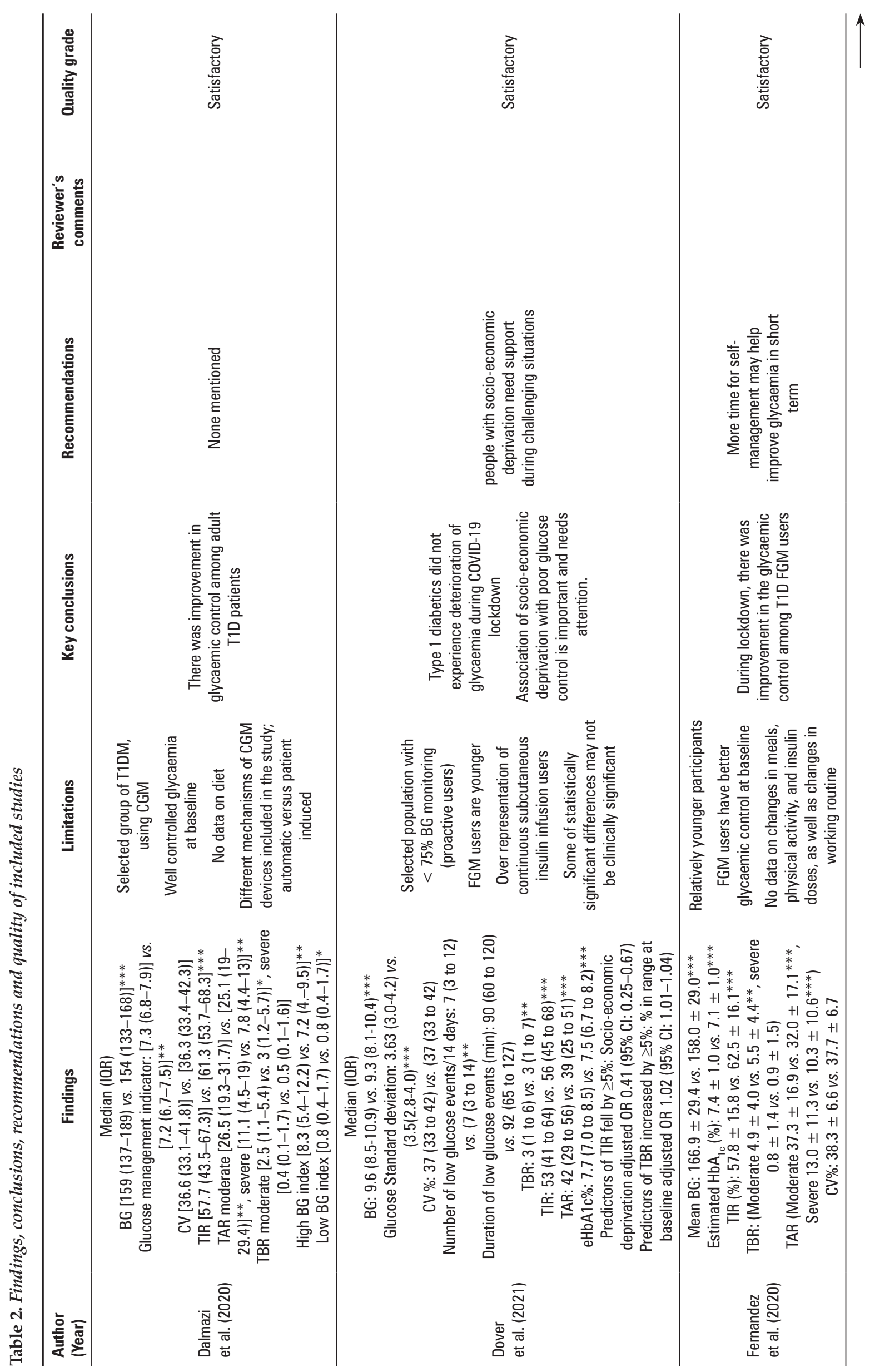




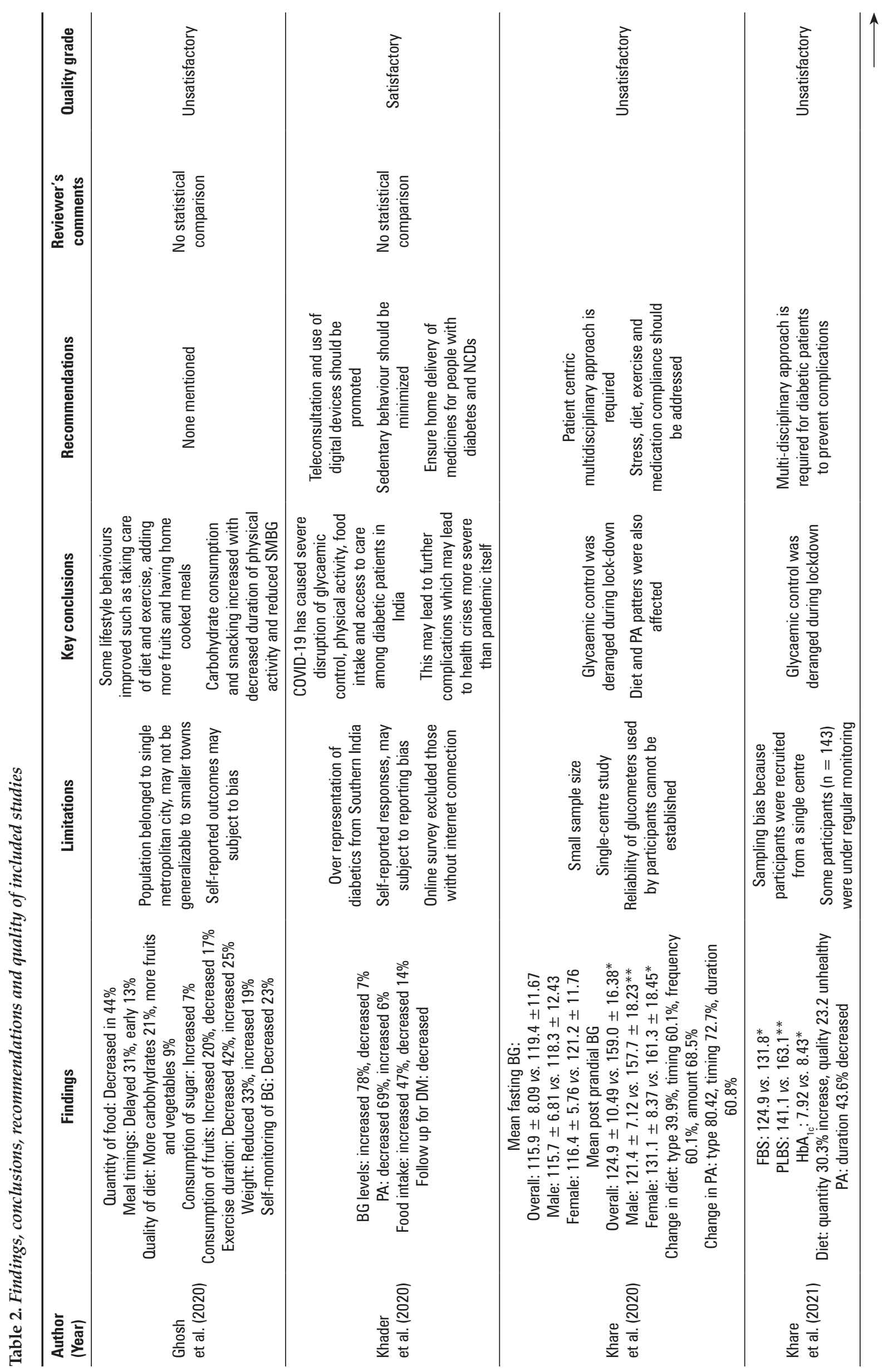




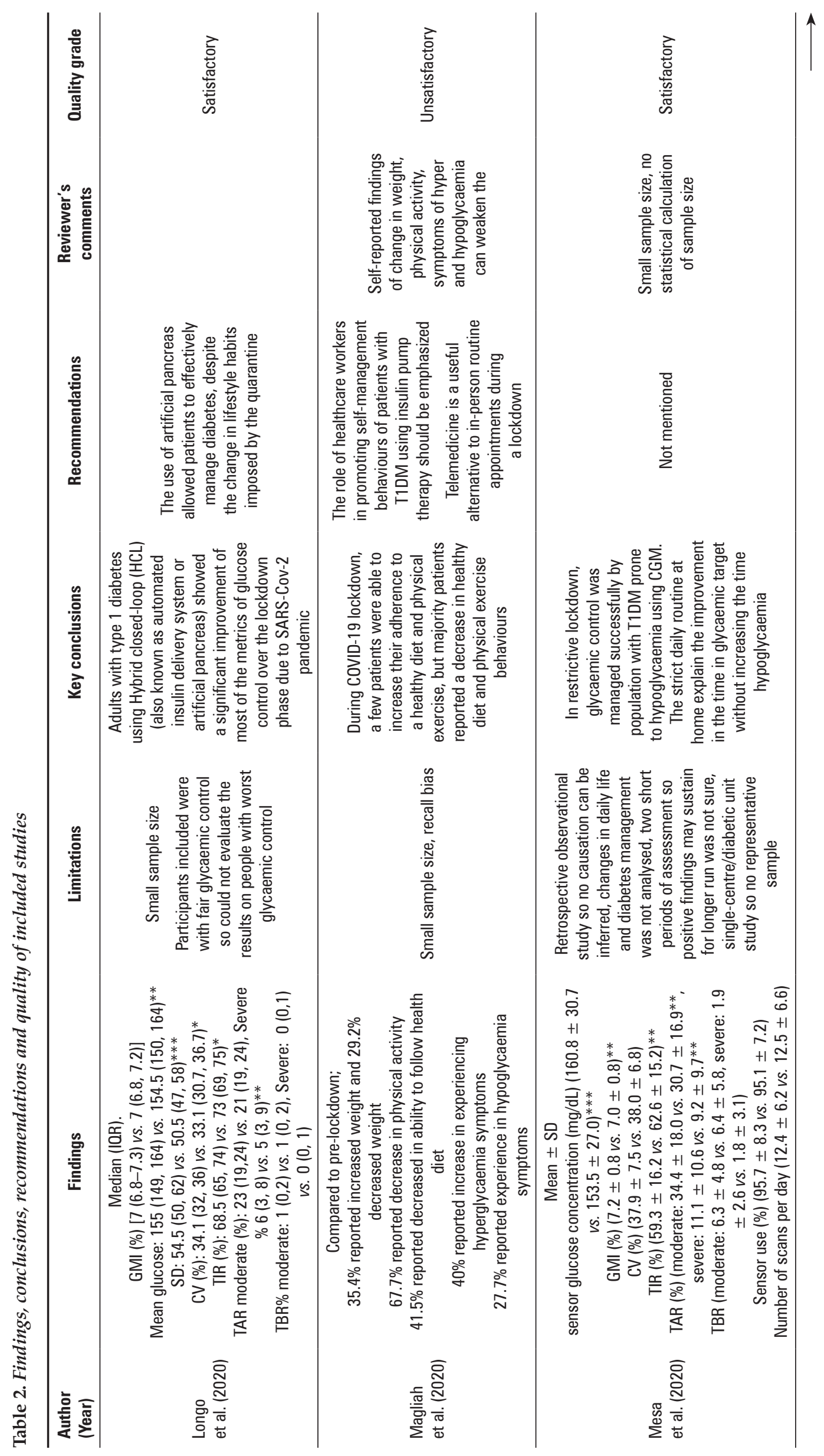




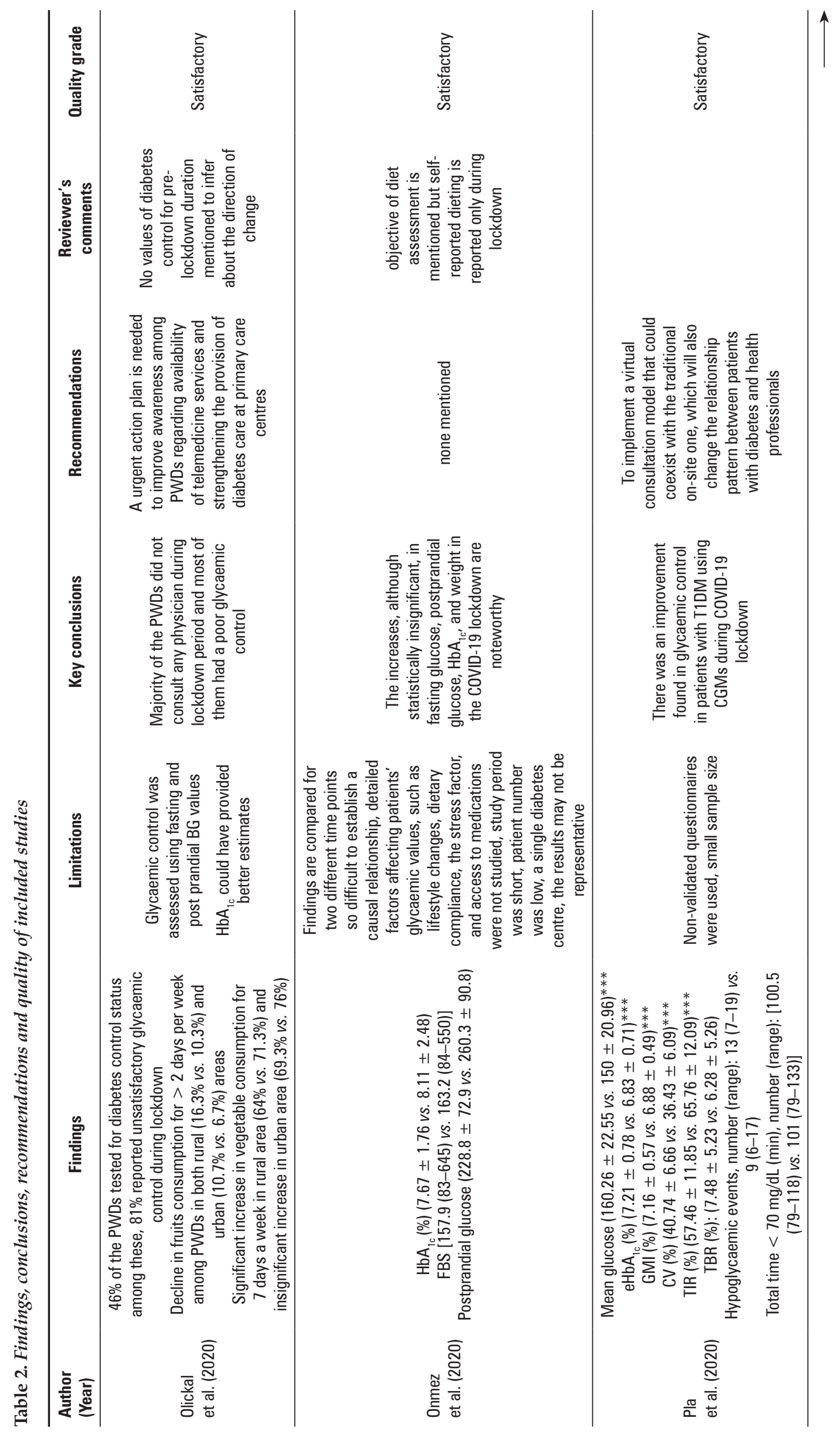




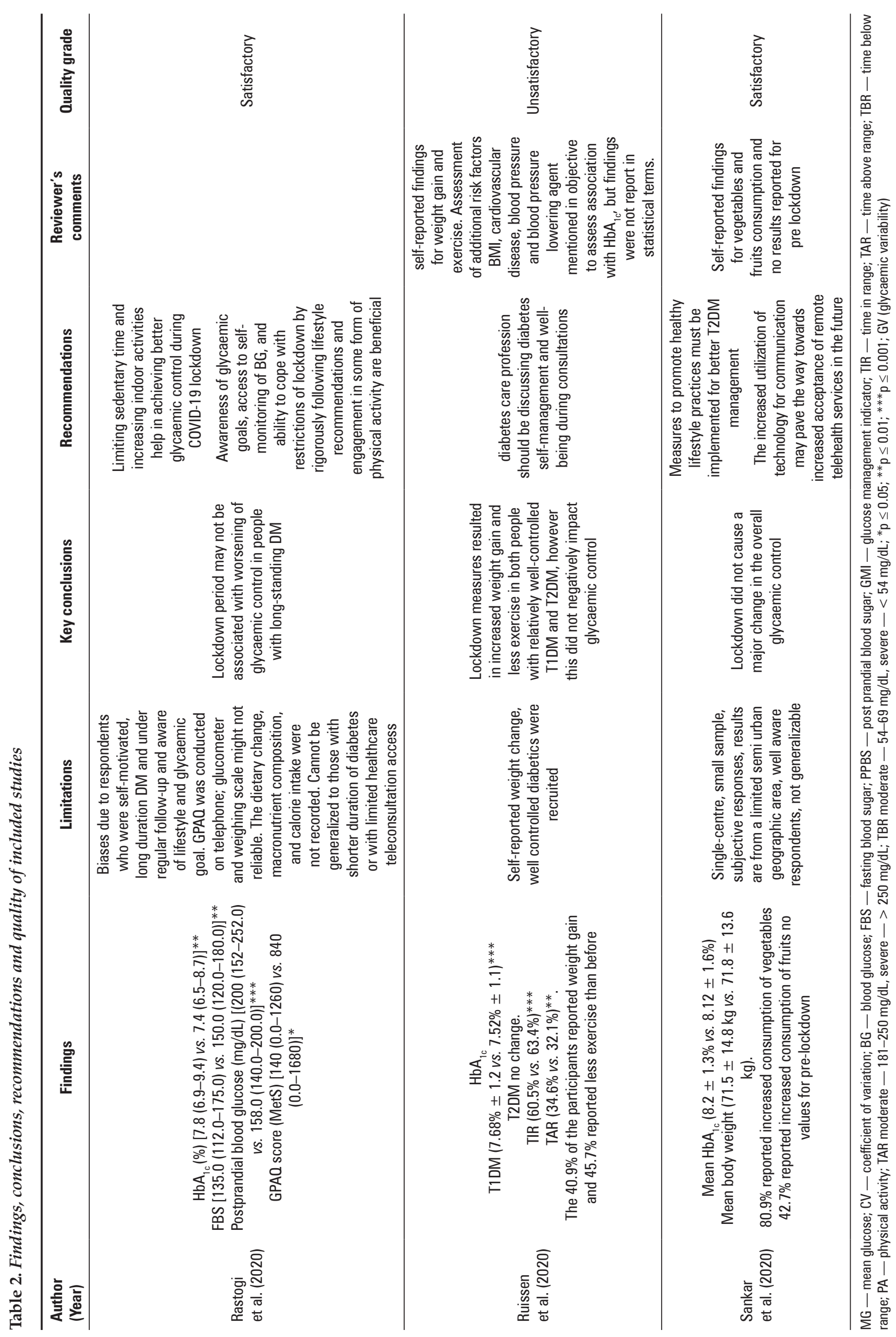


Table 3. Summary of changes in the various para meters included in the review

\begin{tabular}{|c|c|c|c|c|c|c|c|c|c|c|c|c|c|}
\hline \multirow{2}{*}{ Author } & \multirow{2}{*}{ MG } & \multirow{2}{*}{ CV\% } & \multirow{2}{*}{ FBS } & \multirow{2}{*}{ PPBS } & \multirow{2}{*}{$\mathrm{HbA}_{1 \mathrm{c}}$} & \multirow{2}{*}{ GMI } & \multirow{2}{*}{ TIR } & \multicolumn{2}{|c|}{ TAR } & \multicolumn{2}{|c|}{ TBR } & \multirow{2}{*}{ Diet } & \multirow{2}{*}{ PA } \\
\hline & & & & & & & & Moderate & Severe & Moderate & Severe & & \\
\hline $\begin{array}{l}\text { Alshareef et al. } \\
(2020)\end{array}$ & NR & NR & NR & NR & NR & $N R$ & NR & NR & $N R$ & NR & NR & $P$ & $\mathrm{D}$ \\
\hline $\begin{array}{l}\text { Anjana et al. } \\
(2020)\end{array}$ & $N R$ & NR & D & $\mathrm{D}$ & $D$ & NR & $N R$ & NR & NR & NR & NR & NC & $D$ \\
\hline $\begin{array}{l}\text { Aragona et al. } \\
(2020)\end{array}$ & $D$ & NR & NR & NR & NR & $D$ & 1 & \multicolumn{2}{|c|}{ D } & \multicolumn{2}{|c|}{$\mathrm{NC}$} & NR & NR \\
\hline $\begin{array}{l}\text { Assaloni et al. } \\
(2020)\end{array}$ & 1 & NR & NR & NR & NR & NR & NR & NR & NR & NR & NR & NR & $\mathrm{D}$ \\
\hline $\begin{array}{l}\text { Barchetta et al. } \\
(2020)\end{array}$ & 1 & NR & NR & NR & I & NR & $D$ & \multicolumn{2}{|c|}{ I } & \multicolumn{2}{|c|}{ NC } & NR & $D$ \\
\hline $\begin{array}{l}\text { Barone et al. } \\
(2020)\end{array}$ & 1 & NR & $N R$ & NR & NR & NR & NR & NR & NR & NR & NR & NR & $D$ \\
\hline Bonora et al. & D & NC & NR & NR & NR & NR & I & \multicolumn{2}{|c|}{ D } & \multicolumn{2}{|c|}{ NC } & NR & NR \\
\hline (2020) & NC & NC & NR & NR & NR & NR & NC & \multicolumn{2}{|c|}{ NC } & \multicolumn{2}{|c|}{ NC } & NR & NR \\
\hline $\begin{array}{l}\text { Capaldo et al. } \\
(2020)\end{array}$ & NC & $\mathrm{D}$ & NR & NR & NC & NR & 1 & NC & NC & NC & D & C & $D$ \\
\hline $\begin{array}{l}\text { Cotovad-Bellas } \\
\text { et al. (2020) }\end{array}$ & NC & NC & NR & NR & NC & NR & NC & NC & NC & NC & NC & NR & NR \\
\hline $\begin{array}{l}\text { Dalmazi et al. } \\
(2020)\end{array}$ & $\mathrm{D}$ & NC & $N R$ & NR & NR & $D$ & 1 & $D$ & $D$ & I & NC & NR & NR \\
\hline $\begin{array}{l}\text { Dover et al. } \\
\text { (2021) }\end{array}$ & $D$ & NC & NR & NR & D & NR & I & \multicolumn{2}{|c|}{ D } & \multicolumn{2}{|l|}{1} & NR & NR \\
\hline $\begin{array}{l}\text { Fernandez et al. } \\
(2020)\end{array}$ & $D$ & NC & NR & NR & $D$ & NR & I & $\mathrm{D}$ & $D$ & I & NC & NR & NR \\
\hline $\begin{array}{l}\text { Ghosh et al. } \\
(2020)\end{array}$ & NR & NR & NR & NR & NR & NR & NR & NR & NR & NR & $N R$ & C & $D$ \\
\hline $\begin{array}{l}\text { Khader et al. } \\
(2020)\end{array}$ & 1 & NR & NR & NR & NR & NR & NR & NR & NR & NR & NR & $P$ & D \\
\hline $\begin{array}{l}\text { Khare et al. } \\
(2020)\end{array}$ & NR & NR & NC & I & NR & NR & NR & NR & NR & NR & NR & C & C \\
\hline $\begin{array}{l}\text { Khare et al. } \\
(2021)\end{array}$ & NR & NR & I & I & I & NR & NR & NR & NR & NR & NR & $P$ & $D$ \\
\hline $\begin{array}{l}\text { Longo et al. } \\
(2020)\end{array}$ & NR & NR & NR & NR & NR & I & NR & NR & NR & NR & NR & NR & NR \\
\hline $\begin{array}{l}\text { Magliah et al. } \\
(2020)\end{array}$ & NR & NR & NR & NR & NR & NR & NR & I & NR & I & NR & $P$ & $D$ \\
\hline $\begin{array}{l}\text { Mesa et al. } \\
(2020)\end{array}$ & $D$ & NC & NR & NR & NR & $D$ & I & $D$ & $D$ & NC & NC & NR & NR \\
\hline $\begin{array}{l}\text { Olickal et al. } \\
(2020)\end{array}$ & I & $\mathrm{NR}$ & NR & NR & $\mathrm{NR}$ & NR & NR & NR & $\mathrm{NR}$ & NR & NR & C & NR \\
\hline $\begin{array}{l}\text { Onmez et al. } \\
(2020)\end{array}$ & NR & NR & I & I & I & NR & NR & NR & NR & NR & NR & NR & NR \\
\hline $\begin{array}{l}\text { Pla et al. } \\
(2020)\end{array}$ & D & D & NR & NR & D & $D$ & I & NR & NR & NC & NC & NR & NR \\
\hline $\begin{array}{l}\text { Rastogi et al. } \\
(2020)\end{array}$ & NR & NR & I & $D$ & $D$ & NR & NR & NR & $N R$ & NR & NR & NR & I \\
\hline $\begin{array}{l}\text { Ruissen et al. } \\
\text { (2020) }\end{array}$ & NR & NR & NR & NR & $D$ & NR & I & $D$ & $N R$ & NR & NR & NR & $D$ \\
\hline $\begin{array}{l}\text { Sankar et al. } \\
(2020)\end{array}$ & NR & NR & $N R$ & NR & NC & NR & NR & NR & $N R$ & NR & NR & C & NR \\
\hline
\end{tabular}

MG — mean glucose; CV — coefficient of variation; FBS — fasting blood sugar; PPBS — post prandial blood sugar; GMI — glucose management indicator; TIR — time in range; TAR — time above range; TBR — time below range; PA — physical activity; TAR moderate $-181-250 \mathrm{mg} / \mathrm{dL}$; severe — > 250 $\mathrm{mg} / \mathrm{dL}$ );

TBR moderate — 54-69 mg/dL, severe — < 54 mg/dL; NR — not reported; NC — no change; I — increased; D — decreased; C — changed; P — poor 
[15] reported an increase in the physical activity, while five reported a decline in physical activity [17, 26-29].

\section{Association between glycaemic control and changes in diet and physical activity}

A total of eight studies reported blood glucose measurements and dietary changes. Three studies reported increase in blood glucose levels along with poor diet. $[24,25,29]$ One study reported increase in the blood glucose and changes in diet without specification of the direction.[18] Three studies reported no change in glycaemia during change in the diet $[20,23,34]$. One study reported decline in the blood glucose with no change in the diet [17].

Eleven studies reported one or more of the glycaemic indicators and physical activity. Seven studies reported an increase in blood glucose along with reduction in physical activity or changes in diet.[15, 24-29] Three studies reported a decline in blood glucose levels despite a decline in physical activity levels.[16, 17, 20] The direction of changes could not be ascertained in one study [23].

\section{Discussion}

The included studies in this review showed mixed evidence of the impact of COVID-19 lockdown on diabetics. Overall, glycaemic indicators were improved during the pandemic lockdown; as mentioned by the majority of the studies included in this review, physical activity was decreased and dietary patterns were affected. Whereas, the findings from developing countries generally reported that the dietary pattern was affected [18, 22-24, 29, 34], as well as a decline in physical activity $[17,22-24,29]$. One study reported a decrease in $\mathrm{HBA}_{1 c^{\prime}}, \mathrm{FBS}$, and PPBS along with the unexpected finding of decreased physical activity and no change in diet [17]. One study showed increases in all three parameters, i.e. $\mathrm{HBA}_{1 c^{\prime}} \mathrm{FBS}$, and PPBS, along with poor diet and decreased physical activity [24]. Similarly, one study showed an increase in mean glucose levels along with poor diet and decreased physical activity, although the study contained no reporting of other blood glucose parameters ( $\mathrm{HBA}_{1 c^{\prime}}$ FBS, and PPBS) [29]. Another study showed an increase in PPBS, no change in FBS, no reporting of $\mathrm{HBA}_{1 \mathrm{c}}$ and mean glucose, and change in diet and physical activity without mentioning the direction of change [23]. One study reported no change in $\mathrm{HBA}_{1 c}$ but reported a change in diet but without specifying its direction, while no reporting of FBS, PPBS, and mean glucose and physical activity was made [34]. However, one study showed a decrease in PPBS and $\mathrm{HBA}_{1 \mathrm{c}}$ but an increase in FBS and increase in physical activity, whereas, mean glucose and diet were not reported [15]. Henceforth, a variation of reporting a reliable measure, i.e. $\mathrm{HBA}_{1 \mathrm{c}}$ in some studies and reporting severely biased blood glucose parameters in others, of different assessment methods for diet and physical activity, and reporting of anyone outcome from diet and physical activity have led to inconclusive evidence for the determination of an association of $\mathrm{HBA}_{1 \mathrm{c}}$ or glucose with diet and physical activity from the included studies in our review.

Diabetes has been an established risk factor associated with an influenza-related mortality; hence, evidence from a Hong Kong study suggests that mortality rates among people with diabetes from pneumonia exceed mortality rates from cardiovascular disease and cancer $[35,36]$. For that very reason, keeping a compliant lifestyle among diabetic patients during pandemic lockdown must be an unarguably important agenda to deter from avoidable complications that may arise from uncontrolled diabetes [37, 38].

The current review gathered evidence of increased levels of mean glucose, fasting blood sugar, and $\mathrm{HbA}_{1 \mathrm{c}}$ $[13,15,18,24,26-29]$. Overall, the majority of included studies showed well-controlled glucose management indictors and glycaemic parameters. This indicates that patients with diabetes were proactive in maintaining their blood glucose levels during lockdown. Emerging adaptation of online consultation technology could be a way to make patients compliant with their diabetes control measures [39]. However, the accessibility to telemedicine is limited and questionable, and needs to be explored by further research. Another explanation for this improved glycaemia could be the reduced access to fast food due to lockdown and restricted movement.

Physical activity is an important tool to assist in diabetes control; however, evidence shows a reduction in physical activity and prolonged sitting time due to home confinement during the COVID-19 lockdown, which might have a worse metabolic impact on diabetes patients [40, 41]. In our review, comparable findings consisting of a decrease in physical activity were gathered from almost all included studies in the review, which indicates an alarming situation. A meta-analysis suggested that prolonged sitting time and sedentary behaviour were associated with increased risk for diabetes and all-cause mortality [42]. Hence, a dire need for physical activity has been realized lately, and suggestions have been proposed to decrease sedentary behaviour, reduce daily sitting time, and reduce the duration of lying through home-based physical activity programs that are a doable, useful, safe, and effective strategy for diabetes management due to home confinement during the COVID-19 lockdown [43].

The dietary pattern among diabetic patients has been affected due to lockdown, as reported in the ma- 
jority of studies included in this review. This disturbed pattern might not be a positive sign because diet and healthy eating behaviour are crucial for the control of diabetes, and adverse metabolic impact due to unhealthy food consumption and distorted meal patterns during home confinement may have important clinical implications [41]. Comparable findings of unhealthy eating patterns and food consumption have been observed across several settings where lockdowns were implemented [40].

Overall, only three studies showed poor diet [24, $25,29]$, and one reported changes in the diet without specification of the direction [18] along with an increase in blood glucose levels. Moreover, seven studies reported increase in blood glucose along with reduction in physical activity or changes in the diet [15, 24-29]. Three studies reported a decline in blood glucose levels despite a decline in physical activity levels [16, 17, 20]. Therefore, the variation in the included studies' findings to conclude an association between $\mathrm{HBA}_{1 \mathrm{c}}$ or blood glucose, diet and physical activity could be due to methodological bottlenecks, limitations in outcome assessment in non-unanimous and unstandardized form, and majorly the confounders that are not addressed. All these limitations imply inconclusive evidence, and the gaps in the current research call for further exploratory research to identify whether a non-compliant diet or a lower level of exercise, or some other confounding factors, affect the blood glucose levels.

The present review with a comprehensive search has remarkably synthesized important up-to-date and quantitative evidence regarding lifestyle habits among diabetics during the COVID-19 lockdown period, to understand and advocate a comprehensive strategy for them in managing a healthy life pattern. This current synthesis of studies also has the advantage of including the maximum outcome as possible because diabetes is a multi-factorial process.

About two-thirds (68\%) of the studies included in the review had satisfactory quality, which enhances the reliability of the findings included and accurate interpretation of the outcomes. However, this review, despite including a majority of satisfactory quality studies, might be restricted somehow to analysing the impact of the COVID-19 lockdown on daily lifestyle habits of diabetics due to potential sources of bias in the included studies. Firstly, the sampling was based on convenience, without power calculations, which severely affect the representativeness of samples. Secondly, non-validated tools were used for the assessment of physical activity and diet, which are subject to reporting bias. Thirdly, various parameters were used either in combination or alone to assess the glycaemic levels. Out of 17 studies meeting the criteria of good quality, only 7 reported
$\mathrm{HbA}_{1 c^{\prime}}$ which is a more reliable parameter, while other parameters that can be affected by short-term changes in diet were used in most of the studies. The outcome of medication adherence was not mentioned in studies, which is an important outcome variable; however, the deficiency was covered as objective assessment of glucose parameters were reported, and these could be a predictor for medication adherence. Additionally, the scoring assigned to exposure (COVID-19 lockdown) was consistently same as "two" throughout all included studies in-lieu for quality assessment because studies were conducted in lockdown-affected settings. As a result of methodological limitations of included studies meeting the inclusion criteria, robust studies with representative samples and objective assessments are needed to comprehensively explore the impact of $\mathrm{CO}$ VID-19 lockdown on lifestyle and healthy behaviour among diabetic patents.

\section{Conclusion}

The review concludes that lockdown and home confinement due to COVID-19 do not negatively affect the glycaemic control among diabetic patients. There was a decline in the physical activity; however, the evidence was weak about the impact on diet. The current body of evidence is of low quality in terms of the studies' methodological robustness. It is therefore strongly recommended that future studies use robust and objective measurement to avoid biases in the studies and generate strong evidence to draw conclusions and make recommendations for the care of diabetic patients. Nonetheless, there is need to promote indoor physical activity and proper diet, ensure regular supply of anti-diabetic medications, and more importantly regular follow-up with teleconsultation to maintain good glycaemic control among diabetic patients.

\section{Acknowledgement}

The researcher would like to thank the Deanship of Scientific Research, Qassim University for funding the publication fee of this project.

\section{Conflict of interest}

None declared.

\section{Funding}

This research received no external funding.

\section{References}

1. World Health Organization. WHO Coronavirus (COVID-19) Dashboard 2021. https://covid19.who.int/table.

2. Güner R, Hasanoğlu I, Aktaş F. COVID-19: Prevention and control measures in community. Turk J Med Sci. 2020; 50(SI-1): 571-577, doi: 10.3906/sag-2004-146, indexed in Pubmed: 32293835. 
3. Ahmed SA, Ajisola M, Azeem K, et al. Improving Health in Slums Collaborative. Impact of the societal response to COVID-19 on access to healthcare for non-COVID-19 health issues in slum communities of Bangladesh, Kenya, Nigeria and Pakistan: results of pre-COVID and COVID-19 lockdown stakeholder engagements. BMJ Glob Health. 2020; 5(8), doi: 10.1136/bmjgh-2020-003042, indexed in Pubmed: 32819917.

4. Witteveen D, Velthorst E. Economic hardship and mental health complaints during COVID-19. Proc Natl Acad Sci U S A. 2020; 117(44): 27277-27284, doi: 10.1073/pnas.2009609117, indexed in Pubmed: 33046648.

5. Barach P, Fisher SD, Adams MJ, et al. Disruption of healthcare: Will the COVID pandemic worsen non-COVID outcomes and disease outbreaks? Prog Pediatr Cardiol. 2020; 59: 101254, doi: 10.1016/j.ppedcard.2020.101254, indexed in Pubmed: 32837144

6. World Health Organization. COVID-19 significantly impacts health services for noncommunicable diseases 2020 [cited April 07,2021. https:/ www.who.int/news/item/01-06-2020-covid-19-significantly-impacts-health-services-for-noncommunicable-diseases.

7. Saeedi P, Salpea P, Karuranga S, et al. IDF Diabetes Atlas Committee. Global and regional diabetes prevalence estimates for 2019 and projections for 2030 and 2045: Results from the International Diabetes Federation Diabetes Atlas, 9 edition. Diabetes Res Clin Pract. 2019; 157: 107843, doi: 10.1016/j.diabres.2019.107843, indexed in Pubmed 31518657

8. Gujral UP, Johnson L, Nielsen J, et al. Preparedness cycle to address transitions in diabetes care during the COVID-19 pandemic and future outbreaks. BMJ Open Diabetes Res Care. 2020; 8(1), doi: 10.1136/bmjdrc-2020-001520, indexed in Pubmed: 32690631.

9. Peterson J, Welch V, Losos M. The Newcastle-Ottawa scale (NOS) for assessing the quality of nonrandomised studies in meta-analyses. Ottawa Hospital Research Institute, Ottawa 2011

10. Aragona M, Rodia C, Bertolotto A, et al. Type 1 diabetes and COVID-19: The "lockdown effect". Diabetes Res Clin Pract. 2020; 170: 108468, doi: 10.1016/j.diabres.2020.108468, indexed in Pubmed: 32987040.

11. Longo M, Caruso P, Petrizzo M, et al. Glycemic control in people with type 1 diabetes using a hybrid closed loop system and followed by telemedicine during the COVID-19 pandemic in Italy. Diabetes Res Clin Pract. 2020; 169: 108440, doi: 10.1016/j.diabres.2020.108440, indexed in Pubmed: 32926958.

12. Mesa A, Viñals C, Pueyo I, et al. The impact of strict COVID-19 lockdown in Spain on glycemic profiles in patients with type 1 Diabetes prone to hypoglycemia using standalone continuous glucose monitoring. Diabetes Res Clin Pract. 2020; 167: 108354, doi: 10.1016/j.diabres.2020.108354, indexed in Pubmed: 32739380.

13. Önmez A, Gamsızkan Z, Özdemir S, et al. The effect of COVID-19 lockdown on glycemic control in patients with type 2 diabetes mellitus in Turkey. Diabetes Metab Syndr. 2020; 14(6): 1963-1966, doi: 10.1016/j. dsx.2020.10.007, indexed in Pubmed: 33059299.

14. Pla B, Arranz A, Knott C, et al. Impact of COVID-19 Lockdown on Glycemic Control in Adults with Type 1 Diabetes Mellitus. J Endocr Soc. 2020; 4(12): bvaa149, doi: 10.1210/jendso/bvaa149, indexed in Pubmed: 33173841.

15. Rastogi A, Hiteshi P, Bhansali A. Improved glycemic control amongst people with long-standing diabetes during COVID-19 lockdown: a prospective, observational, nested cohort study. Int J Diabetes Dev Ctries. 2020 [Epub ahead of print]: 1-6, doi: 10.1007/s13410-020-00880-x, indexed in Pubmed: 33106739.

16. Ruissen $\mathrm{MM}$, Regeer $\mathrm{H}$, Landstra $\mathrm{CP}$, et al. Increased stress, weight gain and less exercise in relation to glycemic control in people with type 1 and type 2 diabetes during the COVID-19 pandemic. BMJ Open Diabetes Res Care. 2021; 9(1), doi: 10.1136/bmjdrc-2020-002035, indexed in Pubmed: 33431602.

17. Anjana RM, Pradeepa R, Deepa M, et al. Acceptability and Utilization of Newer Technologies and Effects on Glycemic Control in Type 2 Diabetes: Lessons Learned from Lockdown. Diabetes Technol Ther. 2020 22(7): 527-534, doi: 10.1089/dia.2020.0240, indexed in Pubmed: 32522031

18. Olickal JJ, Chinnakali P, Suryanarayana BS, et al. Effect of COVID19 pandemic and national lockdown on persons with diabetes from rural areas availing care in a tertiary care center, southern India. Diabete Metab Syndr. 2020; 14(6): 1967-1972, doi: 10.1016/j.dsx.2020.10.010, indexed in Pubmed: 33059300.

19. Alshareef $\mathrm{R}, \mathrm{Al}$ Zahrani A, Alzahrani A, et al. Impact of the COVID-19 lockdown on diabetes patients in Jeddah, Saudi Arabia. Diabetes Metab Syndr. 2020; 14(5): 1583-1587, doi: 10.1016/j.dsx.2020.07.051, indexed in Pubmed: 32947759.

20. Capaldo B, Annuzzi G, Creanza A, et al. Blood Glucose Control During Lockdown for COVID-19: CGM Metrics in Italian Adults With Type 1 Diabetes. Diabetes Care. 2020; 43(8): e88-e89, doi: 10.2337/dc20-1127, indexed in Pubmed: 32540921.

21. Cotovad-Bellas L, Tejera-Pérez C, Prieto-Tenreiro A, et al. The challenge of diabetes home control in COVID-19 times: Proof is in the pudding. Diabetes Res Clin Pract. 2020; 168: 108379, doi: 10.1016/j. diabres.2020.108379, indexed in Pubmed: 32853692

22. Ghosh A, Arora B, Gupta R, et al. Effects of nationwide lockdown during COVID-19 epidemic on lifestyle and other medical issues of patients with type 2 diabetes in north India. Diabetes Metab Syndr. 2020; 14(5): 917-920, doi: 10.1016/j.dsx.2020.05.044, indexed in Pubmed: 32574982.

23. Khare J, Jindal S, Khare J, et al. Observational study on Effect of Lock Down due to COVID 19 on glycemic control in patients with Diabetes: Experience from Central India. Diabetes Metab Syndr. 2020; 14(6): 1571-1574, doi: 10.1016/j.dsx.2020.08.012, indexed in Pubmed: 32858474.

24. Khare J, Jindal S. Observational study on effect of lock down due to COVID 19 on HBA1c levels in patients with diabetes: Experience from Central India. Prim Care Diabetes. 2021 [Epub ahead of print], doi: 10.1016/j.pcd.2020.12.003, indexed in Pubmed: 33419712.

25. Magliah SF, Zarif HA, Althubaiti A, et al. Managing Type 1 Diabetes among Saudi adults on insulin pump therapy during the COVID-19 lockdown. Diabetes Metab Syndr. 2021; 15(1): 63-68, doi: 10.1016/j. dsx.2020.12.013, indexed in Pubmed: 33310178.

26. Assaloni R, Pellino VC, Puci MV, et al. Coronavirus disease (Covid-19): How does the exercise practice in active people with type 1 diabetes change? A preliminary survey. Diabetes Res Clin Pract. 2020; 166: 108297, doi: 10.1016/j.diabres.2020.108297, indexed in Pubmed: 32623042.

27. Barchetta I, Cimini FA, Bertoccini L, et al. Effects of work status changes and perceived stress onglycaemiccontrol in individuals with type 1 diabetes during COVID-19 lockdown in Italy. Diabetes Res Clin Pract. 2020; 170: 108513, doi: 10.1016/j.diabres.2020.108513, indexed in Pubmed: 33075424.

28. Barone MT, Harnik SB, de Luca PV, et al. The impact of COVID-19 on people with diabetes in Brazil. Diabetes Res Clin Pract. 2020; 166: 108304 doi: 10.1016/j.diabres.2020.108304, indexed in Pubmed: 32623040.

29. Khader MA, Jabeen T, Namoju R. A cross sectional study reveals severe disruption in glycemic control in people with diabetes during and after lockdown in India. Diabetes Metab Syndr. 2020; 14(6): 1579-1584, doi: 10.1016/j.dsx.2020.08.011, indexed in Pubmed: 32858476

30. Bonora BM, Boscari F, Avogaro A, et al. Glycaemic Control Among People with Type 1 Diabetes During Lockdown for the SARS-CoV-2 Outbreak in Italy. Diabetes Ther. 2020 [Epub ahead of print]: 1-11, doi: 10.1007/s13300-020-00829-7, indexed in Pubmed: 32395187.

31. Di Dalmazi G, Maltoni G, Bongiorno C, et al. Comparison of the effects of lockdown due to COVID-19 on glucose patterns among children, adolescents, and adults with type 1 diabetes: CGM study. BMJ Open Diabetes Res Care. 2020; 8(2), doi: 10.1136/bmjdrc-2020-001664, indexed in Pubmed: 33115820.

32. Dover AR, Ritchie SA, McKnight JA, et al. Assessment of the effect of the COVID-19 lockdown on glycaemic control in people with type 1 diabetes using flash glucose monitoring. Diabet Med. 2021; 38(1): e14374, doi: 10.1111/dme.14374, indexed in Pubmed: 32740984.

33. Fernández E, Cortazar A, Bellido V. Impact of COVID-19 lockdown on glycemic control in patients with type 1 diabetes. Diabetes Res Clin Pract. 2020; 166: 108348, doi: 10.1016/j.diabres.2020.108348, indexed in Pubmed: 32711000.

34. Sankar P, Ahmed WN, Mariam Koshy V, et al. Effects of COVID-19 lockdown on type 2 diabetes, lifestyle and psychosocial health: A hospital-based cross-sectional survey from South India. Diabetes Metab Syndr. 2020; 14(6): 1815-1819, doi: 10.1016/j.dsx.2020.09.005, indexed in Pubmed: 32956926.

35. Goeijenbier M, van Sloten TT, Slobbe L, et al. Benefits of flu vaccination for persons with diabetes mellitus: A review. Vaccine. 2017 35(38): 5095-5101, doi: 10.1016/j.vaccine.2017.07.095, indexed in Pubmed: 28807608 .

36. Wu H, Lau ESH, Ma RCW, et al. Secular trends in all-cause and cause-specific mortality rates in people with diabetes in Hong Kong, 2001-2016: a retrospective cohort study. Diabetologia. 2020; 63(4): 757-766, doi: 10.1007/s00125-019-05074-7, indexed in Pubmed: 31942668

37. Bloomgarden ZT. Diabetes and COVID-19. J Diabetes. 2020; 12(4): 347-348, doi: 10.1111/1753-0407.13027, indexed in Pubmed: 32162476.

38. Shin L, Bowling FL, Armstrong DG, et al. Saving the Diabetic Foot During the COVID-19 Pandemic: A Tale of Two Cities. Diabetes Care. 2020; 43(8): 1704-1709, doi: 10.2337/dc20-1176, indexed in Pubmed: 32532755.

39. Ghosh A, Gupta R, Misra A. Telemedicine for diabetes care in India during COVID19 pandemic and national lockdown period: Guidelines for physicians. Diabetes Metab Syndr. 2020; 14(4): 273-276, doi: 10.1016/j. dsx.2020.04.001, indexed in Pubmed: 32283497.

40. Ammar A, Brach M, Trabelsi K, et al. Effects of COVID-19 home confinement on physical activity and eating behaviour Preliminary results of the ECLB-COVID19 international online-survey. Nutrients. 2020; 12(6): 1583, doi: 10.37473/dac/10.1101/2020.05.04.20072447, indexed in Pubmed: 32481594.

41. Martinez-Ferran M, de la Guía-Galipienso F, Sanchis-Gomar F, et al. Metabolic Impacts of Confinement during the COVID-19 Pandemic Due 
to Modified Diet and Physical Activity Habits. Nutrients. 2020; 12(6), doi: 10.3390/nu12061549, indexed in Pubmed: 32466598.

2. Ekelund U, Steene-Johannessen J, Brown WJ, et al. Lancet Physical Activity Series 2 Executive Committe, Lancet Sedentary Behaviour Working Group. Does physical activity attenuate, or even eliminate, the detrimental association of sitting time with mortality? A harmonised meta-analysis of data from more than 1 million men and women. Lancet.
2016; 388(10051): 1302-1310, doi: 10.1016/S0140-6736(16)30370-1, indexed in Pubmed: 27475271.

43. Marçal IR, Fernandes B, Viana AA, et al. The Urgent Need for Recommending Physical Activity for the Management of Diabetes During and Beyond COVID-19 Outbreak. Front Endocrinol (Lausanne). 2020; 11: 584642, doi: 10.3389/fendo.2020.584642, indexed in Pubmed: 33250859 . 